\title{
Influence of probiotic and prebiotic on meat quality of broiler chicken carcasses
}

\author{
Irina Chervonova ${ }^{1, *}$ \\ ${ }^{1}$ Orel State Agrarian University named after N.V. Parahin, 69, Generala Rodina str., Orel, 302019, Russia
}

\begin{abstract}
The article presents the results of studying the impact of the spore-forming probiotic "Olin" and the prebiotic "Ecofiltrum" on the meat quality of broiler chicken carcasses of the Ross308 cross. In the course of the research, it has been found that the inclusion of these preparations in the broiler diet has a positive effect on the studied indicators: the pre-slaughter weight increased by 4.3-5.7\%, the weight of the gutted carcass - by $4.6-6.2 \%$, the muscle weight $-4.8-6.5 \%$, the weight of the loin muscles - by $5.7-8.2 \%$. The ratio of edible parts to inedible parts is 4.14 in the third experimental group, 4.08-in the second, and 4.04-in the control. Based on the results of the anatomical cutting of broiler carcasses and according to the fatness indicators the poultry carcasses of the third and second experimental groups, $87.5 \%$ and $87.2 \%$, respectively, belong to the first grade, and the yield of the first grade carcasses is $86.2 \%$ in the control group. Meat products obtained from both the control poultry and the poultry of both experimental groups has no off-aroma odor and taste, the meat is juicy, tender and aromatic. The products obtained from broiler chickens, whose ration includes the probiotic "Olin" and the prebiotic "Ecofiltrum", do not have any deviations from the established standards and norms. During the research, it has been found that the use of the studied drugs has a positive effect on the meat quality of poultry carcasses. However, broiler chickens receiving the probiotic "Olin" has more pronounced meat qualities.
\end{abstract}

\section{Introduction}

In many countries of the world, poultry farming is one of the most important branches of agriculture, which makes it possible to provide the population with dietary foodstuffs - eggs and meat; moreover, chicken meat is a cheap source of protein [1,2].

For a long time, feed antibiotics have been used as the main drug that improves the use of feed nutrients and increases their digestibility. However, their use has significant drawbacks. It has been established that they could harm human health through poultry products. This turns out to be the most serious problem. Therefore, the use of feed antibiotics has been banned in the countries of the European Union [1,3,4].

In many countries of the world, feed antibiotics have been replaced by environmentally safe biological preparations: probiotics, prebiotics, phytobiotics and others $[5,6,7,8,9,10,11]$. It is noted that such additives can simultaneously stimulate the digestibility and use of nutrients in the feed. They are not accumulated in meat products, and their long-term use does not reduce their effectiveness compared to antibiotics.

In this regard, our paper is aimed to study the effect of the spore-forming probiotic "Olin" and the prebiotic "Ecofiltrum" on the meat quality of broiler chicken carcasses of the Ross-308 cross.

\section{Material and research methods}

As the main object of research we have selected broiler chickens of the Ross- 308 cross, reared for 38 days in the production conditions of the JV "Poultry Meat Production Factory" JSC agro-industrial complex "Orlovskaya Niva". The research scheme is presented in Table 1.

Chickens of the 1st group served as control and did not get the studied preparations. Broiler chickens of the 2nd experimental group got the prebiotic "Ecofiltrum" at a dosage of $0.074 \mathrm{~g} /$ bird. per day in addition to the main diet during the entire raising period, and chickens of the 3rd experimental group got the probiotic "Olin" at a dosage of $0.022 \mathrm{~g} /$ head. per day during the first 15 days of raising. At the poultry farm the studied preparations were manually mixed with feed concentrate before feeding the poultry.

The prebiotic "Ecofiltrum" consists of lactulose, a prebiotic with the highest index of prebiotic activity, and lignin, an effective and physiological sorbent.

The spore-forming probiotic "Olin" contains patented and donated strains of spore-forming microorganisms Bacillus subtilis (VKPM 10172) and Bacillus lisheniformis (VKPM 10135) in a 1:1 ratio, as well as auxiliary substances - lactose and silicon dioxide.

\footnotetext{
* Corresponding author: katya che@bk.ru
} 
Table 1. Research scheme.

\begin{tabular}{|c|c|c|c|}
\hline Group & Poultry population & Duration of raising, days & Experimental conditions \\
\hline 1st control group & 100 & 38 & Basic diet \\
\hline 2nd experimental group & 100 & 38 & $\begin{array}{c}\text { Basic diet }+ \text { "Ecofiltrum" at a dosage of } 0.074 \mathrm{~g} / \mathrm{bird} \\
\text { per day as part of feed concentrate during the entire } \\
\text { raising period }\end{array}$ \\
\hline 3d experimental group & 100 & 38 & $\begin{array}{c}\text { Basic diet + "Olin" at a dosage of } 0.022 \mathrm{~g} / \text { head. per } \\
\text { day as part of feed concentrate during the first } 15 \mathrm{days} \\
\text { of raising }\end{array}$ \\
\hline
\end{tabular}

Microclimate parameters were monitored with the help of generally accepted methods of zoohygienic research. Groups of experimental chickens were separated from the rest of the livestock by screens. Technological parameters (light and temperature conditions, feeding area, drinking water), structure and nutritional value of the feed concentrate corresponded to the recommendations for raising Ross broilers and the recommendations of the Federal Research Center "VNITIP" RAS. It was used 4phase feeding of broilers with complete feed concentrate: starting feed concentrate for the period - 0-10 days, growth feed concentrate- for the period 11-24 days, finish feed concentrate 1 - for the period 26-34 and finish feed concentrate 2 - for the period 35-38 days.

The formulation and implementation of scientific and economic experience was carried out in accordance with [12]. According to [13], the weight of the gutted carcass, the slaughter yield of the gutted carcass, the yield of edible and inedible parts of the carcass, the mass of muscles, including loins, bones and internal fat, were determined.

Statistical data processing was performed using computer programs.

\section{Results and Discussion}

Growth rate is the most significant indicator of broiler chicken meat production. Its value is judged by the change in live weight with age. The experimental bird is weighed to do it. It has been found that the inclusion of both a prebiotic and a probiotic into the technology of raising broiler chickens contributes to an increase in their live weight. The difference in body weight between chickens is insignificant at day-old and there are no significant differences between groups. At 14 days of age, the broilers of the 2nd experimental group outperform the chickens of the 1 st control group by $3.4 \%$ or $14.2 \mathrm{~g}$. The chickens of the 3 rd experimental group have the highest live weight $-444.3 \mathrm{~g}$, which is $4.9 \% \quad(\mathrm{P}<0.05)$ significantly higher than in the control group. At the age of 21 days, the live weight of young birds of both experimental groups is also higher than that of the 1st control group. The difference is $3.3 \%$ and $4.5 \%(\mathrm{P}<0.05)$, respectively. This trend is maintained until the end of broiler raising.

The safety of broiler chickens throughout the entire scientific and economic experience remain high and at the end of the study is $95.0 \%$ in the control group, $97.0 \%$-in the second experimental group, and $98.0 \%$ - in the third experimental group.

At the end of raising a control slaughter of 6 broilers from each group has been carried out (equally divided males and females, close to the average live weight for each group). Deviations from the average live weight do not exceed $2 \%$ in the group. The results of the anatomical broiler dressing, presented in table 2, have shown that the best meat qualities are possessed by the carcasses of chickens from the 3 rd experimental group.

From the presented data, it follows that the introduction of both the prebiotic "Ecofiltrum" and the probiotic "Olin" into the broiler chicken feed ration increased their pre-slaughter weight and, accordingly, the weight of the gutted carcass. So, the pre-slaughter weight is $2189.5 \mathrm{~g}$ in the $2 \mathrm{nd}$ experimental group, $2218.6 \mathrm{~g}-$ in the 3rd, which is $4.3 \%(\mathrm{P}<0.05)$ and $5.7 \%(\mathrm{P}<0.01)$, respectively, higher than the indicator of the control group - $2098.3 \mathrm{~g}$. The weight of the gutted carcass is significantly higher in the experimental groups than the indicator in the control group by $4.6 \%(\mathrm{P}<0.05)-$ in the second experimental group and by $6.2 \%(\mathrm{P}<0.01)-$ in the third group. The increase in the pre-slaughter weight and the weight of the gutted carcass make it possible to obtain in the experimental groups a higher slaughter yield of $73.1-73.2 \%$.

The broiler chickens of the 3rd experimental group have the highest yield of edible parts in broiler carcasses, where this figure is $80.56 \%$ versus $80.32 \%$ and $80.16 \%$, respectively, the chickens of the 2nd experimental group and the control one. The ratio of edible parts to inedible parts is 4.04 in the control group, 4.08-in the 2nd experimental group, 4.14-in the 3rd experimental group. The inclusion of the studied preparations in the diet of broiler chickens contributes to an increase in muscle mass, especially in sirloin. So, the muscle mass is $993.3 \mathrm{~g}$ in the 2 nd experimental group, $1008.8 \mathrm{~g}-$ in the $3 \mathrm{rd}$, and the fillet weight $-360.5 \mathrm{~g}-$ in the 2 nd and 369.2 
$\mathrm{g}$ - in the 3rd group, which, respectively, is higher than the values of the control group by $4.8 \%(\mathrm{P}<0.05)$, and
$6.5 \%(\mathrm{P}<0.01)-$ in the first indicator and by $5.7 \%$ ( $\mathrm{P}$

$<0.05)$ and $8.2 \%(\mathrm{P}<0.01)-$ in the second.

Table 2. Meat quality of broiler chicken carcasses (age -38 days; $n=6$ ).

\begin{tabular}{|c|c|c|c|}
\hline \multirow{2}{*}{ Ratio } & \multicolumn{3}{|c|}{ Group } \\
\hline & 1st control group & 2nd experimental group & $3 \mathrm{~d}$ experimental group \\
\hline Pre-slaughter weight, $\mathrm{g}$ & $2098.3 \pm 22.4$ & $2189.5 \pm 23.6^{*}$ & $2218.6 \pm 21.9 * *$ \\
\hline Gutted carcass weight, $g$ & $1529.7 \pm 16.4$ & $1600.5 \pm 15.9^{*}$ & $1624.0 \pm 17.3^{* *}$ \\
\hline Slaughter output of gutted carcass, $\%$ & 72.9 & 73.1 & 73.2 \\
\hline Weight of edible parts of the carcass, $g$ & $1226.2 \pm 13.9$ & $1285.5 \pm 14.8^{*}$ & $1308.3 \pm 14.4^{* *}$ \\
\hline Mass of inedible parts of a carcass, $g$ & $303.5 \pm 8.4$ & $315.0 \pm 8.0$ & $315.7 \pm 8.1$ \\
\hline $\begin{array}{l}\text { Yield of edible parts to the weight of the gutted } \\
\text { carcass, } \%\end{array}$ & 80.16 & 80.32 & 80.56 \\
\hline $\begin{array}{l}\text { Yield of inedible parts to the weight of the gutted } \\
\text { carcass, } \%\end{array}$ & 19.84 & 19.68 & 19.44 \\
\hline Ratio of edible parts to inedible parts & 4.04 & 4.08 & 4.14 \\
\hline Muscle mass, $g$ & $947.5 \pm 11.4$ & $993.3 \pm 10.9 *$ & $1008.8 \pm 11.6^{* *}$ \\
\hline incl. fillet & $341.1 \pm 6.1$ & $360.5 \pm 5.0^{*}$ & $369.2 \pm 5.6 * *$ \\
\hline Muscle yield to gutted carcass weight, \% & 61.94 & 62.06 & 62.12 \\
\hline Bone mass, $\mathrm{g}$ & $301.2 \pm 3.6$ & $311.5 \pm 3.1$ & $311.8 \pm 3.8$ \\
\hline Bone yield to gutted carcass weight, $\%$ & 19.69 & 19.46 & 19.20 \\
\hline Ratio of muscle mass to bone mass & 3.15 & 3.19 & 3.24 \\
\hline Interior fat mass, $g$ & $20.5 \pm 0.46$ & $21.1 \pm 0.41$ & $21.3 \pm 0.48$ \\
\hline Ratio of interior fat to gutted carcass weight, $\%$ & 1.34 & 1.32 & 1.31 \\
\hline \multicolumn{4}{|l|}{ Grade, \% } \\
\hline I grade & 86.2 & 87.2 & 87.5 \\
\hline II grade & 13.8 & 12.8 & 12.5 \\
\hline
\end{tabular}

Note. ${ }^{*}-\mathrm{P}<0.05 ; * *-\mathrm{P}<0.01$.

The quality indicators of meat and its nutritional value depend on the nutritional status of the poultry. Each carcass is assigned a certain grade (I or II) according to its condition. The first grade includes poultry carcasses with good muscle development, a rounded chest shape, with subcutaneous fat depositions on the chest and abdomen, with a non-prominent keel of the sternum. In carcasses of the second grade, the muscles are satisfactorily developed, the pectoral muscles with the keel form an angle without depressions, and the absence of fat depositions is allowed, a slightly protruding keel of the sternum. The results of anatomical cutting of broiler carcasses indicate that according to the fatness indicators of the poultry carcass of the 2 nd experimental group, it can be attributed to the 1 st grade by $87.2 \%$, and the 3rd by $87.5 \%$, and the yield of 1 st grade carcasses in the control is $86.2 \%$.
Thus, analyzing the results of the control slaughter and anatomical broiler dressing, it should be emphasized that the broiler chickens of the 3rd experimental group, having the probiotic "Olin" in the feed concentrate at a dosage of $0.022 \mathrm{~g} /$ bird. per day during the first 15 days of raising, have more pronounced meat qualities.

The chemical analysis results of experimental group muscles of broilers make it possible to establish that the inclusion of both the spore-forming probiotic "Olin" and the prebiotic "Ecofiltrum" in the diet of chickens promote an increase in protein in their pectoral and leg muscles. Thus, in the third experimental group the protein content in the pectoral muscles of broilers exceedes the same indicator in the control by $1.16 \%$, and in the legs - by $0.91 \%$, and in the second group - by $1.12 \%$ and $0.86 \%$, respectively.

There is a tendency to a decrease in the level of fat in the muscles of broiler chickens feeding with the studied 
dietary supplements. So, the fat content is $1.69-1.75 \%$ in the breast muscles of broiler chickens, and 3.28-3.51\%-in the legs, and $1.83 \%$ and $3.58 \%$-in the control, respectively.

The meat of broiler chickens of both experimental groups has a higher biological value in comparison with poultry meat of the control group. The use of the probiotic and prebiotic increases tryptophan levels, especially in the breast muscles of broiler chickens. At the same time, the values of the protein-quality indicator of the most valuable breast muscles of broilers exceed the control by $0.56-0.61$ and $0.38-0.42$ units, respectively, in the experimental groups.

To determine the palatability of broiler meat when using a probiotic and a prebiotic, tasting has been carried out, the results of which are evaluated on a five-point scale. All prototypes are rated higher by the tasters than the samples from the control group. Thus, fried meat from the pectoral muscles of the second experimental group exceeds the same indicator of the control sample by 0.21 points, fried meat from the leg muscles - by 0.28 points, boiled meat from the pectoral muscles - by 0.15 points, boiled meat from the leg muscles - by 0.18 points, and the third experimental group - by $0.24,0.31,0.16$ and 0.20 , respectively. The poultry meat of the third experimental group gets a higher total tasting score.

There are almost no differences between the control and experimental samples when evaluating the broth. The broiler broth from the third experimental group gets 4.48 points during tasting, which is the highest score among all the evaluated broth samples.

It should be especially noted that there is no obvious difference in taste or aroma between all meat products. Thus, it has been found that meat products obtained from both control poultry and poultry of both experimental groups do not have extraneous odors and taste, the resulting meat is characterized by juiciness, tenderness and aroma. The products obtained from broiler chickens, whose ration includes the probiotic "Olin" and the prebiotic "Ecofiltrum", do not have any deviations from the established standards and norms.

\section{Conclusions}

During the research, it has been found that the use of both the probiotic "Olin" and the prebiotic "Ecofiltrum" has a positive effect on the meat quality of poultry carcasses: the pre-slaughter weight increased by $4.3-5.7 \%$, the weight of the gutted carcass - by $4.6-6.2 \%$, the muscle weight - n 4.8-6.5\%, the mass of loin muscles - by 5.7$8.2 \%$. The ratio of edible parts to inedible parts is 4.14 in the third experimental group, 4.08-in the second, and 4.04-in the control. Based on the results of the anatomical broiler dressing and according to the fatness indicators the poultry carcasses of the third and second experimental groups, $87.5 \%$ and $87.2 \%$, respectively, belong to the I grade, and the yield of the I grade carcasses is $86.2 \%$ in the control.

The meat products obtained from both the control poultry and the poultry of both experimental groups have no extraneous odors and taste, the resulting meat is characterized by its juiciness, tenderness and aroma. It should be noted that the introduction of the probiotic "Olin" into the feed concentrate during the first 15 days of their raising in the amount of $0.022 \mathrm{~g} /$ head per day makes it possible to obtain the best results.

\section{References}

1. N.R. Sarangi, L.K. Babu, A. Kumar, C.R. Pradhan, P.K. Pati, J.P. Mishra, Veterinary World 3 313-319 (2016)

2. L.M. Roiter, Ya.S. Roiter, A.G. Akopyan, IOP Conference Series: Earth and Environmental Science 315022067 (2019)

3. V.S. Buyarov, I.V. Chervonova, V.V. Mednova, I.N. Ilyicheva, Bulletin of Agrarian Science 3 (84) 44-59 (2020)

4. M.M.J. Arsène, A.K.L. Davares, S.L. Andreevna, E.A. Vladimirovich, B.Z. Carime, R. Marouf, I. Khelifi, Veterinary World 14(2) 319-328 (2021)

5. V.I. Fisinin, A.S. Ushakov, G.K. Duskaev, N.M. Kazachkova, B.S. Nurzhanov, Sh.G. Rakhmatullin, G.I. Levakhin, Agricultural biology 2 385-392 (2018)

6. N. Khochamit, S. Siripornadulsil, W. Siripornadulsil, P. Sukon, Veterinary World 12 2663-2672 (2020)

7. V.S. Buyarov, S.Yu. Metasova, The Kazan University scientific notes. Series: Natural sciences 3 408-421 (2019)

8. S. Lebedev, A.Yu. Nikitin, V.I. Fisinin, I.A. Egorov, I.S. Miroshnikov, V.A. Ryazanov, V.V. Grechkina, O.V. Kvan, IOP Conference Series: Earth and Environmental Science 341012077 (2019)

9. L.N. Skvortsova, A.G. Koshchaev, V.I. Shcherbatov, Yu.A. Lysenko, V.I. Fisinin, I.P. Saleeva, S.F. Sukhanova, International Journal of Pharmaceutical Research 4760 (2018)

10. V.I. Fisinin et al., Nutrition issues 6 114-124 (2017).

11. I.A. Egorov, V.G. Vertiprakhov, T.N. Lenkova, V.A. Manukyan, T.A. Egorova, A.A. Grozina, Bioscience Research 4 4144-4149 (2020)

12. V.S. Lukashenko et al. Research methodology for the eggs and poultry meat production (Sergiev Posad: The All-Russian Scientific Research and Technological Institute of Poultry Farming, 2015)

13. V.S. Lukashenko et al. Methodology for anatomical cutting of carcasses, organoleptic parameters of the quality of meat and eggs of poultry and morphology of eggs (Sergiev Posad: The All-Russian Scientific Research and Technological Institute of Poultry Farming, 2013) 